\title{
РЕЛИГИОЗНО-ФИЛОСОФСКАЯ АНТРОПОЛОГИЯ МОСКОВСКОЙ ШКОЛЫ ДУХОВНО-АКАДЕМИЧЕСКОГО ТЕИЗМА
}

Ю.А. Корнилов

\begin{abstract}
На основании рукописей курсовых и кандидатских сочинений московских духовных школ представлено своеобразие реакции их представителей при конструировании собственных моделей религиозно-философской антропологии. Раскрыто существо взгляда московских философов-теистов на изменение роли и места человека в природе и обществе, при этом анализируются физические и душевные возможности и способности человека при сохранении базовых принципов библейской и христианской антропологии.
\end{abstract}

Ключевые слова: духовно-академический теизм, естествознание, человеческая природа, дихотомия, трихотомия.

\section{RELIGIOUS AND PHILOSOPHICAL ANTHROPOLOGY OF THE MOSCOW SCHOOL OF SPIRITUAL AND ACADEMIC THEISM}

Yu.A. Kornilov

On the basis of manuscripts of thesis and Candidate's dissertation of Moscow theological schools, the peculiarity of the reaction of their representatives when constructing their own models of religious and philosophical anthropology is presented. The essence of the view of Moscow philosophers-theists on the change in the role and place of man in nature and society is revealed. The physical and mental capabilities and abilities of a person are analyzed, while maintaining the basic principles of biblical and Christian anthropology.

Keywords: Spiritual and academic theism, natural science, human nature, dichotomy, trichotomy.

В XIX в. в связи со стремительным развитием естествознания в Европе наступает период переосмысления научных, культурных, экономических и социальных основ жизни. Естественно, философия как в целом, так и в частных своих проявлениях не стала исключением в этих процессах. Новые естественно-научные открытия физических и душевных возможностей человека требовали корреляции с философскими антропологическими системами. По мнению С.В. Пишуна, одним из основополагающих философских течений XIX в., внесших наибольший вклад в систематизацию интерпретации духовных, психических и материальных процессов, является русская духовно-академическая философия (духовно-академический теизм) [18: с. 86]. В настоящей статье мы рассмотрим реакцию в философскоантропологических воззрениях представителей московского духовно-академического теизма второй половины XIX в. на естественно-научную революцию на примере рукописей кандидатских и курсовых сочинений московских духовных школ.

Априори можно было бы сделать вывод, что при всей критической настроенности естественно-науч- ного знания XIX в. к любым представителям христианской философской традиции, ценностно сопряженной с библейскими текстами, ответная реакция представителей духовно-академического теизма должна быть соответствующе резко отталкивающей и не приемлющей достижений в различных областях естествознания, которые переворачивали взгляд на человека и его место в мироздании. Но в случае московского духовно-академического теизма ситуация с вышеобозначенной полемикой более сложна и интересна. Например, в разборе статьи «О древности рода человеческого» говорится о враждебности к Библии естествознания, которое хочет освободиться от «Божественного откровения». Подчеркивается, что такое стремление похвально, но должно быть в определенных границах своей компетентности. Оправдание такому стремлению видится в том, что Библия «не имеет своей целью распространение научных сведений» [5: л. 44].

Стоит отметить, что профессора московских духовных школ требовали от учащихся не только глубокого знания современных им естественнонаучных достижений, но и того, как эти достиже-

Корнилов Юрий Анатольевич (Иеромонах Марк) - старший преподаватель кафедры теологии Департамента философии и религиоведения Дальневосточного федерального университета (г. Владивосток), аспирант кафедры философии, социологии и права Дальневосточного государственного университета путей сообщения (г. Хабаровск).

Kornilov Yuri Anatolyevich (Hieromonch Mark) - Senior Lecturer of the Department of Theology, Department of Philosophy and Religious Studies of the School of Arts and Humanities at Far Eastern Federal University, Post-graduate student of the Department of Philosophy, Sociology and Law at Far Eastern State Transport University.

E-mail: markir-x@yandex.ru 
ния уже повлияли на различные философские концепции. Например, профессор Московской духовной академии С.С. Глаголев в своем отзыве на одну из студенческих работ подчеркивает, что «автор не знаком с современными учениями о природе» и не вполне выяснил, что понимать под философией природы, и указывает на естественно-научные ошибки, а также ошибочные выводы о природе человека, которые за этим последовали [9: л. 2-4]. К сожалению, сама студенческая работа не сохранилась, чтобы оценить степень ошибочности выводов студента. Тот же Глаголев разносит книгу Светлова, представленную на соискание докторской степени, за ошибочные естественно-научные суждения. При этом предлагает, чтобы Светлов «сжег те страницы, где приводит свои ошибочные суждения», но позже хвалит за исследовательский энтузиазм [8: л. 4]. Другая работа - о формировании нравственного облика человека посредством экономических составляющих. В этом сочинении проводится мысль, что развитие труда способствует развитию нравственности, но только тогда, когда развиваются обе его составляющие: индивидуальная и коллективная. Если развивается только первая, тогда развивается эгоизм, если только вторая, тогда отсутствует творчество и, следовательно, развитие замедляется [22: л. 41]. На это рецензент отмечает, что в итоге суждения автора неосторожны и односторонни, хотя обращает внимание на использование индуктивного метода исследования, соотнося физико-экономические и нравственные явления [7: л. 1]. Похожие ситуации показывают, что закрытые защиты студенческих работ более свободны от цензуры и соответственно более продуктивны в формировании новых взглядов и концепций на антропологию в духовно-академическом теизме. Однако это не хаотичное развитие антропологии, а контролируемое развитие библейской антропологии в московских духовных школах с сохранением свежести и смелости мысли. Для отображения ситуации с цензурой можно привести случай из истории Киевской школы духовноакадемического теизма, когда публичная защита докторской диссертации архимандрита Филарета была запрещена Святейшим синодом по причине того, что цензоры нашли сильное влияние немецкой библеистики. Подобные решения могли серьезно отразиться на дальнейшей научной и исследовательской деятельности и, следовательно, могли сковывать развитие мысли традиционными, как они тогда понимались, православными философско-антропологическими взглядами. Таким образом, можно сделать вывод, что для полемики по естественно-научным вопросам представителям духовно-академического теизма требовалась серьезная подготовка. Это было необходимо, чтобы ограничить использование в спорах с позитивистами и материалистами, опиравшимися на новейшие достижения наук, не всегда достаточно аргументируемой доказательной базы.

В одной из курсовых работ студента Московской духовной академии С. Смирнова затрагивался взгляд позитивистов и материалистов на природу и происхождение органической жизни в целом, и на человека в частности, как на «машину», которая управляется инстинктами, возникающими в соответствии с их физическим устроением. Чем «искуснее устроение», тем сложнее и разнообразнее инстинкты [21: л. 40-42]. Данный взгляд, основанный на теории эволюции Дарвина, продиктован желанием показать, что человек есть лишь закономерный этап развития органической жизни под воздействием внешней среды. Автор показывает, что одна и та же внешняя среда формирует совершенно разные организмы, и человек не является продуктом воздействия внешних сил. Автор пишет, что сущность человека как венца органической жизни не в том, что во внешней стороне он представляет из себя в высшей степени искусно устроенную «машину», а именно в том внутреннем принципе жизни, который не только движет эту «машину», но и изменяет, обновляет, усовершенствует ее ввиду своих целей и в силу собственного саморазвития [20: л. 149]. Еще один взгляд на внутренний мир человека разбирается в статье «Душа и действующие силы природы», автор которой опровергает взгляд на тело человека как на ряд гальванического столба, в котором душа - это гальваническая сила, из чего следует, что «душа лишь развитие физических сил природы» [5: л. 43].

В общем и целом для антропологии московского духовно-академического теизма характерно неприятие взгляда на внутренний мир человека, на его душу как на инстинкт, рефлекс, «развитие физических сил природы», приспособление к внешней среде. Такой взгляд разбирается не только касательно теории эволюции Дарвина, но и на примере эволюционизма Г. Спенсера в работе К. Словенского, в которой он замечает, что «эволюции необходимо доказать, что особенной субстанции для психической жизни не нужно ... и для этого Спенсер необходимо ассимилирует высшие проявления души с рефлексами» [18: л. 116]. Стоит отметить, что опровержение теории эволюции не всегда было удачным по причине ангажированности идеи [10: л. 106]. Хотя встречались и емкие замечания. С.С. Глаголев в своём отзыве писал о популярности и распространённости дарвинизма, а следовательно, и часто встречающихся в работах опровержений на него, от которых Глаголев, видимо, устал, потому и подытожил: «Широкий успех дарвинизма объясняется тем, что он стоит ниже всех когда-либо возникав- 
ших философий природы. Дарвинизм не дает объяснений ничему, поэтому ничему и не противоречит» [16: л. 2]. Все же критическим замечаниям подвергаются не только ученые, которые не всегда компетентно обращаются с духовно-академической антропологией, но и представители последней, когда вторгаются в естественно-научные области, им не свойственные. В этом видится одна из проблем противоречий [1: л. 8].

Несмотря на все вышесказанное, духовноакадемический теизм не отвергает совершенно очевидный факт принадлежности человека к животному органическому миру, а подвергает критике попытку сведения антропологии лишь к законам животного существования. В нескольких сохранившихся работах этих вопросов касаются следующим образом. Так, представитель Московской духовной академии Н. Часоводов не отрицает психической жизни у животных и пишет, что «животных постепенно наделяют всеми психическими свойствами, которыми обладает человек. Вся разница в том, что у животных они не столь сильно развиты [23: л. 46]. Животные обладают умом, но не способны к абстрактному мышлению, следственно, лишены самосознания [23: л. 101]. Той же проблемы самосознания касается А. Архангельский, отмечавший, что «человек, глубоко сродный по своей природе с миром животных, тем существенно отличен от животных, что ему дано было осознать себя в этой своей ограниченности» [3: л. 10]. Осознание этой ограниченности Архангельский видит в том, что есть «роковая двойственность человеческого существа, определяемая совмещением в человеке двух начал: безусловного и условного», что детерминировано тем, что человек был создан ограниченным фактически, т.е. актуально, и безграничным идеально, т.е. потенциально [3: л. 11]. Таким образом постоянно подчеркивается двойственность человеческой природы, которая позволяет человеку сложные соотношения с окружающей его средой, что отмечает в своей работе другой московский исследователь-теист К. Нарбеков, писавший о том, что «жизнь человеческой природы по своему существу есть известное соотношение или общение человека с разными - соответственно разным сторонам его сложной природы - сторонами внешней, по отношению к этой природе, среды» [17: л. 4].

Антропологические рассуждения о сложности человеческой природы в духовно-академическом теизме сводятся к дихотомии (душа и тело) или трихотомии (дух, душа и тело) человеческой природы. Принципиальность приверженности к концепции двухсоставности или трехсоставности человеческой природы имеет значение только в контексте целей и задач антропологических построений. В основном используется дихотомическая мо- дель, по причине того, что, как было отмечено выше, основные сомнения естествознания касались наличия в человеке психической субстанции. Одну из проблем определения наличия души видят в ее проявлении в деятельности человека. По мнению И. Куняева, душа человека без отношения к материальному миру, посредством соответственного устроенного тела, должна остаться «без всякого действования» [14: л. 2-3]. Таким образом, он подчеркивает, что деятельность души человека легко свести к физиологической деятельности. О причинах сложности наблюдения за дихотомией человеческой природы А. Каэлас в своём кандидатском сочинении указывал следующее: «Христианская этика предполагает как параллелизм, так и взаимодействие души и тела в человеке, при основном понимании этих начал как двух отдельных и реально различных, но внутренне тожественных деятелей» [13: л. 214]. Говоря о взаимоотношении души и тела, он подчеркнул, что их действительное активное взаимоотношение мыслимо в человеке только при таком понимании природы этих начал, которое сохраняет их раздельное существование как отдельных деятелей, но, вместе с тем, не доводит это разделение до субстанционального противоположения [13: л. 210]. Тем самым автор намекает на различение, а не абсолютное разделение деятельных проявлений дихотомии устроения человека. Кроме того, А. Каэлас высказывает мнение, что некоторые стороны понимания вопроса о взаимоотношении души и тела могут иметь значение для научного обоснования христианского понимания как самой сущности вселенной, так и ее жизни [13: л. 209]. К сожалению, данную мысль в сохранившейся работе он не развивает, а другие работы данного автора не сохранились. Подобный подход встречается также в работе Н. Андроникова, в которой он соотносит образ взаимодействия души и тела, монотеистического Бога и вселенной: «Если душа, как существо простое, не может действовать на тело, которое есть сложное существо, то и Бог, как существо простое, не может действовать на мир, как существо сложное» [2: л. 4]. Таким сравнением Н. Андроников подчеркивает, что простота души затрудняет ее изучение для человеческого ума, который на момент XIX в. в акте познания расчленяет объект познания на составные части.

В духовно-академическом теизме рассуждения о человеке достаточно тесно связаны с библейским повествованием о сотворении мира. Естественнонаучные концепции XIX в. или ставили под сомнение библейское видение человеческой природы, или отвергали его. По этому поводу основные тезисы представителей московского духовно-академического теизма сводились к следующему:

1. Противоречие между наукой и библейским повествованием о творении человека заключается в 
самом понимании последнего, а потому устранению этих противоречий может служить более глубокое исследование этого повествования, буквально - его «расшифровка».

2. На основании согласия научных сведений и библейского повествования о сотворении человека можно сделать вывод, что по мере развития и совершенствования научного антропогенеза будет совершенствоваться понимание библейской антропологии [6: л. 59].

При этом православные исследователи часто признавали как несомненный факт поступательное развитие научного познания относительно библейского ветхозаветного периода. В. Голубев пишет о том, что первобытный человек при объяснении физических явлений руководствуется прежде всего сознанием своей воли как единственно доступной его непосредственному внутреннему воззрению движущей, координирующей и субординирующей вещи причины [6: л. 2]. Он же приводит справедливое для познания древнего человека утверждение: «...без сомнения, внешние органы чувств часто дают нам ошибочные показания образа существования феноменов, но они не могут нас обмануть относительно самого факта существования вещи» [6: л. 123]. Тем самым показывается, что в настоящее время человеку более доступно познание явлений самих по себе. Кроме того, были замечания по поводу компетентности естественных наук XIX в. Во-первых, перечисляются вопросы, на которые наука не может дать ответа, говоря о природе пространства и времени [15: л. 160-166]. Во-вторых, молодой московский учёный-теист А. Смирнов писал, что «если точные исследования природы на настоящий момент (конец XIX в.) представляются противоречащими Библии, то или потому, что неправильно понимаются, или не верно принимаются за точные результаты, или потому, что Библия неправильно понимается, или, наконец, потому вообще, что естественные науки сделали еще очень мало» [20: л. 14]. При этом здесь речь идет не об аннулировании естественно-научных достижений, а о трезвом взгляде на них, в том числе и о взгляде на устройство человека. Стоит отметить, что А. Смирнов, проанализировав естественно-научные достижения, пришел к выводу, что «и в настоящем состоянии наука, как и возможно для нее будущем состоянии, оставляет непререкаемым следующую главную истину, что человек есть не только последний член в видимом творении, но и цель всего видимого творения» [20: л. 18]. Также встречается мысль, видящая в несовершенстве человеческого познания средство для бесконечного развития: «Человеческая наука по одному тому, что она человеческая, не совершенна, она постепенно приближается к идеалу совершенства, но никогда его не достигнет, ибо в противном случае прекратилось бы дальнейшее научное движение [1: л. 21].

Кроме реакции на естественно-научные открытия, встречаются работы, которые рассматривают больше социальные процессы, но в настоящее время их можно отнести к гендерной антропологии. Например, Работа В. Барбарина на более чем 700 страницах затрагивает проблему эмансипации и равенства полов как с физиопсихической, так и с социальной точки зрения. При этом характер его аргументации постоянно тяготеет к опоре на многовековые традиции, нежели к серьезному анализу проблемы. Хотя один из его выводов выглядит интересным для рассмотрения. В нем автор говорит об опасности огрубения женщин на «общественной площади деятельности». Следовательно, женщина может потерять благотворные влияния на нравственно-эстетическую сторону мужчин общества [4: л. 366].

Примером размышлений о причинности смерти человеческой природы может служить кандидатское сочинение В. Знаменского. Даже соглашаясь с естественно-научными описаниями причин смертности человеческого существа, которые в настоящее время являются несостоятельными, автор предлагает осмыслить причины смерти человека в ценностных категориях: две причины смертности человека: внутренняя и внешняя. Внутренняя заключается в постоянном, неудержимом стремлении быть властелином вселенной, овладеть всем, насладиться всем, на что наша телесность не рассчитана - на такие непрекращающиеся усилия всем овладеть. Внешняя причина заключается в мире, который своими горизонтами манит человека к этому бесконечному стремлению к наслаждению миром [11: л. 98-99].

Таким образом, из вышеизложенного можно установить основные особенности антропологии московского духовно-академического теизма второй половины XIX в., сформировавшейся в условиях кризиса старой философской метафизики:

1) большинство представителей духовно-академического теизма, рассматривающих те или иные проблемы антропологии, старались оставаться в рамках своей компетенции, осмысляя законы человеческого существования;

2) духовно-академический теизм пресекает дилетантство и неуместную эйфорию вседозволенности в антропологических естественно-научных построениях, при этом отмечая естественность процесса сомнений и отказа от традиционной христианской антропологии;

3) большинство работ естественно-научного характера в духовно-академическом теизме, которые заявляют о решении космогонических, экзегетических, гносеологических и других проблем, по сути своей антропоцентричны и рассматривают антро- 
пологические вопросы, что подтверждает мысль С.В. Пишуна о том, что идею человека русские теисты выводят из идеи мира [18: с. 87];

4) антропология духовно-академического теизма чаще всего касается вопросов существования души человека и ее природы;

5) соотношение антропологии и космологии рассматривается в контексте дихотомических построений духовно-академического теизма;

6) особые требования к антропологической полемике заключаются в серьезном и глубоком изучении естественно-научных, в основном эволюционных, антропологических теорий XIX в.

\section{ЛИТЕРАТУРА}

1. Автономов, Н. Космогония Моисея в сравнении с новейшим естествознательным учением о происхождении солнечной системы / Н. Автономов. - Москва, 1888 // Отдел рукописей Российской государственной библиотеки (далее - ОР РГБ). - Ф. 172. - К. 164. - Е.х. 11. - 135 л.

2. Андроников, Н. Рассуждение о способе соединения души с телом / Н. Андроников // ОР РГБ. - Ф. 172. - К. 171. - Е.х. 7. -8 л.

3. Архангельский, $A$. Типы диссолюционных воззрений в церковной письменности и светской науке / А. Архангельский. - Москва, 1913 // ОР РГБ. - Ф. 172. - К. 174. - Е.х. 1. 271 л.

4. Барбарин, В. Равноправность человеческих полов перед судом Священного Писания и науки / В. Барбарин. Москва, 1882 // ОР РГБ. - Ф. 172. - К. 177. - Е.х. 5. - 375 л.

5. Волко, В. Критический обзор апологетической литературы в русской духовной журналистике / В. Волко // ОР РГБ. - Ф. 172. - К. 213. - Е.х. 3. - 12 л.

6. Голубев, В. Библейское учение о творении мира из ничего / В. Голубев. - Москва, 1901 // ОР РГБ. - Ф. 172. К. 224. - Е.х. 6. -286 л.

7. Городенский, H. Отзыв на студенческую работу Г. Староверова «Значение экономических и физических условий жизни для нравственности» / Н. Городенский. Москва, 1899 // ОР РГБ. - Ф. 172. - К. 403. - Е.х. 8. - 1 л.

8. Глаголев, С. Отзыв о представленной на соискание степени доктора богословия книге Светлова «Курс апологетического богословия» / С. Глаголев. - Москва, 1902 // ОР РГБ. - Ф. 172. - К. 461. - Е.х. 14. - 8 л.

9. Глаголев, С. Отзыв на студенческую работу С. Богоявленского «Философия природы св. Василия Великого» / С. Глаголев // ОР РГБ. - Ф. 172. - К. 189. - Е.х. 10. - 4 л.
10. Давидович, В. Дни творения и эволюция / В. Давидович // ОР РГБ. - Ф. 172. - К. 232. - Е.х. 5. - 184 л.

11. Знаменский, В. Богословское учение и естественнонаучные мнения о смерти человека, ее происхождение и значение / В. Знаменский. - Москва, 1903 // ОР РГБ. Ф. 172. - К. 251. - Е.х. 21. - 121 л.

12. Кашираников, В. Учение пророков о внешней природе, о человеке и об общественном быте в мессианские места / В. Кашираников. - Москва, 1911 // ОР РГБ. - Ф. 172. К. 264. - Е.х. 23. - 231 л.

13. Каэлас, A. Воззрения Декарта, окказионалистов и Спинозы на взаимоотношение духа и тела, их дальнейшее развитие и значение для научного обоснования христианского мировоззрения / А. Каэлас. - Москва, 1905 // ОР РГБ. - Ф. 172. - К. 265. - Е.х. 1. -215 л.

14. Куняев, И. Рассуждение о составе существа человеческого / И. Куняев // ОР РГБ. - Ф. 172. - К. 280. - Е.х. 3. 10 л.

15. Курганский, М. Природа в религиозном воззрении русского народа (проблема космологии космогонии) / М. Курганский. - Москва, 1912 // ОР РГБ. - Ф. 172. - К. 280. - Е.х. 11. - 201 л.

16. Мышицын, В. Отзыв о сочинении С. Глаголева «Сверхъестественное откровение и естественное богопознание вне истинной церкви» / В. Мышцын. - Москва, 1901 // ОР РГБ. - Ф. 172. - К. 460. - Е.х. 4. - 16 л.

17. Нарбеков, $K$. Учение св. отцов IV в. о природе первозданного человека / К. Нарбеков. - Москва, 1898 // ОР РГБ. - Ф. 172. - К. 313. - Е.х. 5. - 158 л.

18. Пишун, C.B. Антропология русского духовноакадемического теизма XIX в. / С.В. Пишун // Социальные и гуманитарные науки на Дальнем Востоке. - 2009. № 3 (23). - С. 86-91.

19. Словенский, $K$. Психология эволюционизма Спенсера / К. Словенский. - Москва, 1889 // ОР РГБ. - Ф. 172. К. 380. - Е.х. 10. - 128 л.

20. Смирнов, А. Об отношении Моисеева повествования о сотворении мира / А. Смирнов. - Москва, 1874. // ОР РГБ. - Ф. 172. - К. 381. - Е.х. 1. - 54 л.

21. Смирнов, С. Целесообразность устройства мира как одно из доказательств бытия Божия / С. Смирнов. - Москва, 1897. // ОР РГБ. - Ф. 172. - К. 385. - Е.х. 6. - 156 л.

22. Староверов, Г. Значение экономических и физических условий жизни для нравственности / Г. Староверов. Москва, 1899 // ОР РГБ. - Ф. 172. - К. 403. - Е.х. 5. - 116 л.

23. Часоводов, Н. Страдание твари (опыт философского комментария... ) / Н. Часоводов. - Москва, 1906 // ОР РГБ. Ф. 172. - К. 430. - Е.х. 6. -234 л. 